\title{
Electro-thermal Modelling of Multichip Power Modules for High Power Converter Application
}

\author{
Mohammad Shahjalal", Hua Lu and Chris Bailey \\ Department of Mathematical Sciences, University of Greenwich \\ 30 Park Row, London, SE10 9LS, United Kingdom \\ †M.Shahjalal@gre.ac.uk
}

\begin{abstract}
In a compact power electronics systems such as converters, thermal interaction between components is inevitable. Traditional RC lumped modelling method does not take that into account and this would cause inaccuracy in the predicted temperature in the components of the systems. In this work, numerical simulation have been used to obtain detailed temperature distribution in power devices and the parameters for a Foster network behavior thermal model are extracted so that the thermal interaction can be accounted for and the model can be used to predict temperatures at all critical layers of the components. An ad-hoc conventional three-phase voltage source inverter (DC to $\mathrm{AC}$ converter) with a rating of $7.8 \mathrm{KW}$ has been studied in this work as an example of the application of the proposed framework. The key component in the converter is a $75 \mathrm{~A} / 1200 \mathrm{~V}$ rated IGBT module. A power electronics circuit simulator is used to predict the power losses in the IGBT module and a Finite Element Analysis software is used to obtain the transient temperature profile in the module and the behaviour thermal model parameters are extracted using curve-fit approach. The resulting combined electro-thermal model is analysed using the circuit simulator again to obtain the temperature for various loading conditions. The results show that the proposed method can significantly improve the accuracy of predicted temperatures in the IGBT modules.
\end{abstract}

Keywords-Electro thermal model, inverter, IGBT, power module, circuit simulator, finite element analysis, power electronics

\section{INTRODUCTION}

Power Electronic converters that contain multichip power modules are widely used in applications such as hybrid electric vehicles and wind power energy conversion. In many applications converters are required to operate efficiently and reliably in harsh environment and under very high current/voltage loading [1]- [2]. Significant improvement in semiconductor technology has accelerated the increase in the power handling/processing ability of converters but the design, manufacturing, and application of these converters have met some challenges. One of the most important challenges is to meet the stringent reliability requirements for power electronics semiconductor devices such as IGBT (Insulated Gate Bipolar Transistor) modules. Because of the high power density, great time-varying losses are produced in power semiconductor devices and that results in high temperature and degradation in the devices [3]. The failure modes in IGBT modules include bond-wire lift off and solder fatigue [4] and the modules' lifetime is mainly determined by the junction temperature. Therefore, detailed knowledge about the temperature in power electronic components under application loading conditions is important in power module reliability prediction and in improving the design of the modules. There are several commonly used methods in thermal analysis. These include the Computational Fluid Dynamics (CFD), Finite Element Analysis (FEA), Finite Difference, analytic approach, and lumped parameter equivalent thermal resistor-capacitor (RC) network approach. The numerical methods such as FEA [5]- [6] and CFD [7] can provide accurate spatial temperature distribution but it is time-consuming and it is therefore not suitable for predicting temperature for the long time-varying load profiles. The analytical approach is based on solving partial differential equations using Fourier series [8]- [10]. It is accurate and fast but it can only be used for solving heat conduction in simple geometries and it can't model the heat convection between the heat sink and coolant accurately.

In the lumped parameter $\mathrm{RC}$ network method, the heat transfer process is represented by a circuit that consists of thermal resistors, capacitors and heat sources [11]. The thermal circuits are easy to implement and can be analysed using circuit simulators that are normally used for solving electric circuit problems. The present form of this method, however, cannot solve complex problems such as the heat transfer in multichip power modules [12]. Another issue of the method is that the parameters in the lumped parameter model are usually derived from manufacturer's data and they are not temperature dependent. Furthermore the method does not take into account of thermal coupling between components or the thermal spreading effect. On top of those issues, manufacturer's data are based on certain boundary conditions which may differ in real converter design applications. These issues affect the prediction accuracy, particularly in cases where temperature variations are great (e.g. from room temperature to hundreds of degrees). This inaccuracy in temperature prediction will affect reliability analysis/estimation of converters because the junction temperature is the most critical factor in the performance of power module reliability.

In this paper an improved electro-thermal modelling method has been proposed for accurate temperature prediction in IGBT modules. Finite Element Analysis is used to solve time dependent heat transfer in the power modules and the results are used to obtain refined parameters for the construction of RC Foster thermal network. By using this method, thermal coupling 
between critical layers of components can also be taken into account and therefore the temperature prediction accuracy can be improved. The RC Foster network can be analyzed using a circuit simulator PLECS [13].An IGBT power module with two diodes and two IGBTs has been analysed in order to demonstrate the application of the proposed methodology. The IGBT is assumed to be a component in conventional threephase voltage source $\mathrm{DC}$ to $\mathrm{AC}$ inverter with a rating of 7.8 KW.

\section{THE METHODOLOGY}

\section{A. Modelling Framework}

The proposed modelling framework is shown in Fig. 1. A circuit simulator is used to simulate the current/voltage and the electrical losses in the converter for the given converter topology and the prescribed load profile. Together with the details of the IGBT module, the losses are fed into an FEM software to calculate the time-dependent temperature distribution in the module and this is then used for the extraction of the Foster thermal network parameters. The power losses can also be estimated using simple power loss models [12]. The thermal network can be analysed using a circuit simulator to predict the temperatures at a number of locations of interest in the IGBT module.

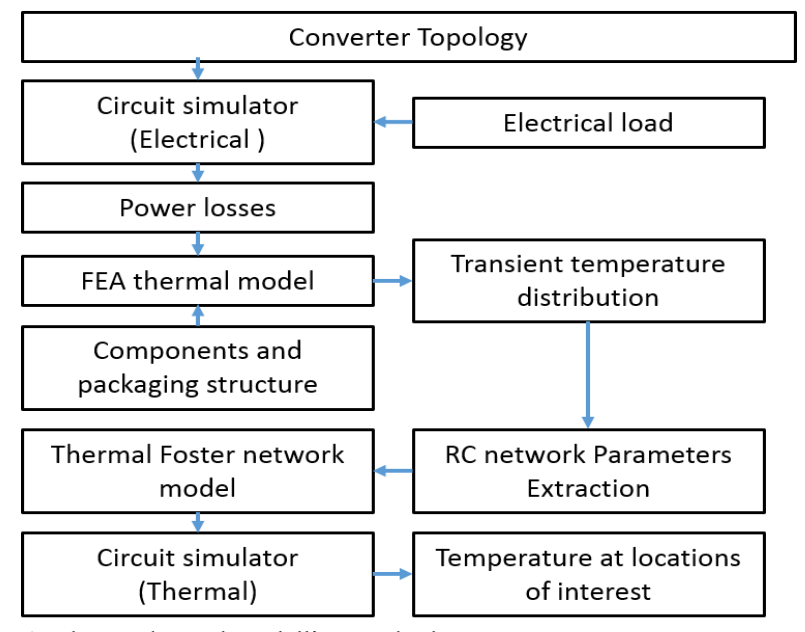

Fig. 1. Electro-thermal modelling method

\section{B. System configuration and basics of the modelling}

The IGBT module is assumed to be Semikron's SKM75GB123D [14] which has a rating of 1200V/75A. There are two IGBT devices and two antiparallel diodes forming a half bridge configuration. To construct the three-phase voltage source DC to AC inverter, three half bridge modules are required but in this work, only one IGBT module has been analyzed. In a SKM75GB123D IGBT module, both IGBT chips are soldered to a Direct Bond Copper (DBC) substrate and a thermal interface material (e.g. thermal grease) is applied between the baseplate and the heatsink to improve physical integrity and heat transfer. A schematic of the cross-sectional of an IGBT module is shown in Fig. 2, and the material properties are listed in Table I.

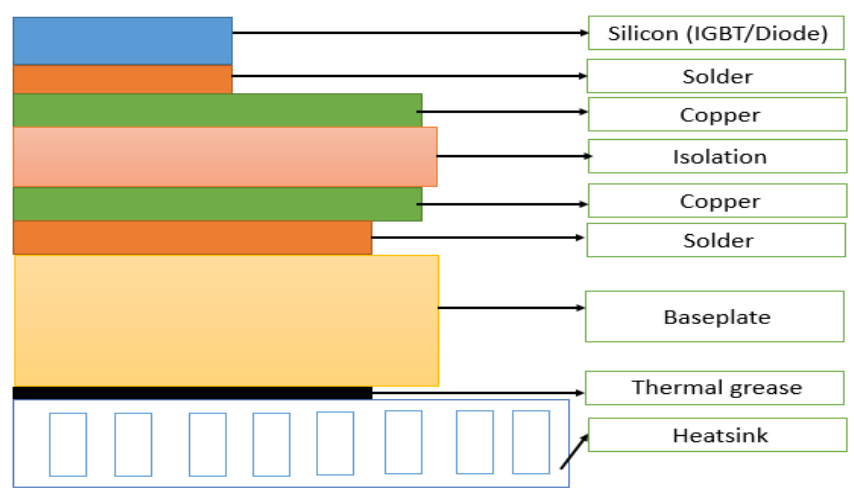

Fig. 2. Simplified Cross-sectional view of IGBT module: SKM75GB123D

Table I IGBT Module material properties and dimension details [14]

\begin{tabular}{|c|c|c|c|c|}
\hline Material & $\begin{array}{l}\text { Volume, } \\
\mathrm{L}^{*} \mathrm{~W} * \mathrm{t} \\
\left(\mathrm{mm}^{3}\right)\end{array}$ & $\begin{array}{c}\text { Density, } \\
\mathrm{kg} / \mathrm{m}^{3}\end{array}$ & $\begin{array}{l}\text { Specific } \\
\text { heat } \\
\text { capacity, } \\
\mathrm{J} / \\
(\mathrm{kg} . \mathrm{K})\end{array}$ & $\begin{array}{c}\text { Thermal } \\
\text { Conductivity, } \\
W /(m . K)\end{array}$ \\
\hline $\begin{array}{c}\text { IGBTs } \\
(\mathrm{Si} i)\end{array}$ & $9 * 9 * 0.4$ & 2329 & 700 & 140 \\
\hline $\begin{array}{c}\text { Diodes } \\
(\mathrm{Si})\end{array}$ & $6 * 6 * 0.4$ & 2329 & 700 & 140 \\
\hline Solderl & $\begin{array}{c}\text { As } \\
\text { chips } * 0.053\end{array}$ & 0.053 & As chips & 35 \\
\hline $\begin{array}{l}\text { Copper } \\
\text { layerl }\end{array}$ & $28 * 25 * 0.35$ & 8700 & 385 & 360 \\
\hline $\begin{array}{l}\text { Ceramic } \\
\left(\mathrm{Al}_{2} \mathrm{O}_{3}\right)\end{array}$ & $30 * 27 * 0.636$ & 3260 & 740 & 100 \\
\hline $\begin{array}{l}\text { Copper } \\
\text { layer2 }\end{array}$ & $28 * 25 * 0.35$ & 8700 & 385 & 360 \\
\hline Solder2 & $28 * 25 * 0.103$ & 9000 & 150 & 35 \\
\hline $\begin{array}{c}\text { Baseplate } \\
(\mathrm{Cu})\end{array}$ & $91 * 31 * 3$ & 8700 & 385 & 280 \\
\hline $\begin{array}{c}\text { Thermal } \\
\text { grease }\end{array}$ & $91 * 31 * 0.1$ & 1180 & 1044 & 1 \\
\hline
\end{tabular}

\section{Modelling of thermal interaction}

An IGBT and a diode in the IGBT module are represented by a thermal network, and the other IGBTs and diodes are assumed to be inactive for simplicity. The thermal network consists of some third order RC pairs to represent the heat transfer behaviours of each material layer between two nodes. It also contain the heat sources that represent the power losses in the IGBT and the diode. The nodes of the network correspond to the critical material interfaces.

To extract the parameters for the RC pairs, the thermal impedance of each layer between two nodes is required. These can be extracted from FEA thermal modelling of the IGBT module. The thermal parameter extraction process based on FEA derived time-dependent temperature responses has been demonstrated in $[15,16]$. The process uses the transformed thermal impedance responses. Two FEA simulations have been performed to obtain the thermal responses due to self-heating and cross-heating in the IGBT-diode pair. In the first simulation, only the IGBT is active and in the second only the diode is active. From the results, the self-heating and crossheating thermal impedance response curves at selected thermal network nodes are derived. These selected nodes correspond to the locations at the centres of the selected material interfaces as 
well as the top and bottom of the whole structure. The nodes that correspond the top of the chip, the interface of chip and chip solder, the interface of substrate solder and baseplate, the bottom of the baseplate are denoted by letters ' $p$ ', ' $q$ ', ' $r$ ', 's ' respectively (Fig.3). Lower subscript ' $I$ ' and ' $D$ ' denote the IGBT and diode respectively. In the following, the upper subscript ' $j$ ', ' $c S$ ' , ' $b s$ ', ' $b$ ' respectively denote the junction, chip solder, baseplate solder, and the baseplate layers respectively, and the temperatures at these selected locations for the IGBT and diode are $T_{j I p}, T_{j D p}, T_{c s I q}, T_{c s D q}, T_{b s I r}, T_{b s D r}$, $T_{b I s}$, and $T_{b D s}$ respectively.

\section{Thermal Interaction Model}

In matrix form, the relationship between power losses and the IGBT and diode temperatures can be written as

$$
\left[\begin{array}{c}
T_{j-I} \\
T_{j-D}
\end{array}\right]=\left[\begin{array}{cc}
Z_{\text {thI }}^{\text {self }} & Z_{\text {thI-D }}^{\text {cross }} \\
Z_{\text {thD-I }}^{\text {cross }} & Z_{\text {thD }}^{\text {self }}
\end{array}\right] *\left[\begin{array}{l}
P_{\text {losses }-I} \\
P_{\text {losses }-D}
\end{array}\right]+\left[\begin{array}{c}
T_{a} \\
T_{a}
\end{array}\right]
$$

where, $T_{j-I}$ and $T_{j-D}$ are the junction temperature in IGBT and diode respectively, $Z_{t h I}^{\text {self }}$ and $Z_{t h D}^{\text {self }}$ are the total self-heating thermal impedance of the IGBT and diode respectively, $Z_{t h I-D}^{\text {cross }}$ and $Z_{t h D-I}^{\text {cross }}$ are the total cross-heating thermal impedance of IGBT-diode and diode-IGBT respectively, and $P_{\text {losses-I }}$ and $P_{\text {losses-D }}$ are the losses in IGBT and diode respectively and $T_{a}$ is the ambient temperature.

The self-heating impedances of the IGBT and the diode can be expressed by Eqs. $2 \& 3$, and the cross-coupling impedances are expressed by Eqs. $4 \& 5$. The meanings of the impedances are explained in Fig. 3 and Table II.

$$
\begin{aligned}
& Z_{t h I}^{s e l f}=Z_{t h I}^{j-c s}+Z_{t h I}^{c s-b s}+Z_{t h I}^{b s-b}+Z_{t h I}^{b-h} \\
& Z_{t h D}^{\text {self }}=Z_{t h D}^{j-c s}+Z_{t h D}^{c s-b s}+Z_{t h D}^{b s-b}+Z_{t h D}^{b-h} \\
& Z_{\text {thI-D }}^{\text {cross }}=Z_{\text {thI-D }}^{j-c s}+Z_{t h I-D}^{c s-b s}+Z_{t h I-D}^{b s-b}+Z_{t h I-D}^{b-h} \\
& Z_{\text {thD-I }}^{\text {cross }}=Z_{\text {thD-I }}^{j-c s}+Z_{t h D-I}^{c s-b s}+Z_{t h D-I}^{b s-b}+Z_{t h D-I}^{b-h}
\end{aligned}
$$

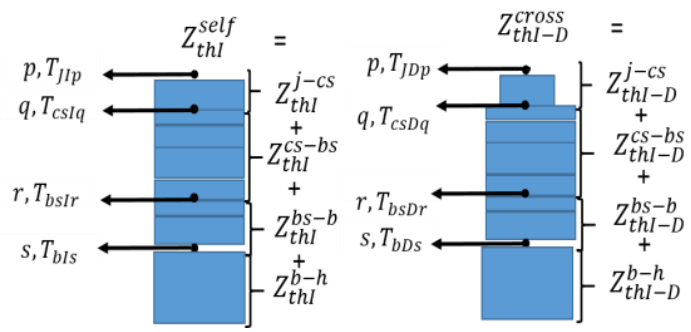

Fig. 3. The total IGBT self-heating and diode cross-heating thermal impedances and the impedances for the material layers.

Table II: Thermal impedance symbols.

\begin{tabular}{|l|l|}
\hline Symbols & Meaning \\
\hline$Z_{t h I}^{j-c s}, Z_{t h D}^{j-c s}$ & $\begin{array}{l}\text { Self-heating impedance of IGBT and Diode between } \\
\text { junction and chip solder }\end{array}$ \\
\hline$Z_{t h I}^{c s-b s}, Z_{t h D}^{c s-b s}$ & $\begin{array}{l}\text { Self-heating impedance of IGBT and Diode between } \\
\text { chip solder and baseplate solder }\end{array}$ \\
\hline$Z_{t h I}^{b s-b}, Z_{t h D}^{b s-b}$ & $\begin{array}{l}\text { Self-heating impedance of IGBT and Diode between } \\
\text { baseplate solder and baseplate }\end{array}$ \\
\hline$Z_{t h I}^{b-h}, Z_{t h D}^{b-h}$ & $\begin{array}{l}\text { Self-heating impedance of IGBT and Diode between } \\
\text { baseplate and heatsink }\end{array}$ \\
\hline$Z_{t h I-D}^{j-c s}, Z_{t h D-I}^{j-c s}$ & $\begin{array}{l}\text { Cross-heating impedance of IGBT-Diode and Diode- } \\
\text { IGBT between junction and chip solder }\end{array}$ \\
\hline
\end{tabular}

\begin{tabular}{|l|l|}
\hline$Z_{t h I-D}^{c s-b s}, Z_{t h D-I}^{c s-b s}$ & $\begin{array}{l}\text { Cross-heating impedance of IGBT-Diode and Diode- } \\
\text { IGBT between chip solder and baseplate solder }\end{array}$ \\
\hline$Z_{t h I-D}^{b s-b}, Z_{t h D-I}^{b s-b}$ & $\begin{array}{l}\text { Cross-heating impedance of IGBT-Diode and Diode- } \\
\text { IGBT between baseplate solder and baseplate }\end{array}$ \\
\hline$Z_{t h I-D}^{b-h}, Z_{t h D-I}^{b-h}$ & $\begin{array}{l}\text { Cross-heating impedance of IGBT-Diode and Diode- } \\
\text { IGBT between baseplate and heatsink }\end{array}$ \\
\hline
\end{tabular}

The extraction of RC network parameters from derived transient thermal impedance responses are described in details in the following sections.

\section{FOSTER THERMAL NETWORK PARAMETERS}

\section{A. FEA thermal analysis}

In order to extract the thermal impedance values at selected layers, two transient FEA simulations have been carried out in which the power loss of either the IGBT or the diode is used as the only heat source. The power loss values are $110 \mathrm{~W}$ and $60 \mathrm{~W}$ for the IGBT and the diode respectively [12] and they are applied at the top surface of the IGBT/diode chips. It is assumed that the module is mounted on a liquid-cooled cold-plate and in this simulation a convective heat transfer boundary condition is applied at the bottom of the baseplate and the heat transfer coefficient and the ambient temperature are $3000 \mathrm{~W} /\left(\mathrm{m}^{2} \mathrm{~K}\right)$ and $20^{\circ} \mathrm{C}$ respectively.

The temperature distributions at $\mathrm{t}=100 \mathrm{~s}$ simulation time and the transient responses at selected locations from the two simulations are shown in Fig. 4. It is worth pointing out that there is a delay for the cross-heating impedances at the beginning. That is because the chips share the same substrate as the baseplate, and it takes time for the heat to spread/propagate from one chip to the other. The temperature responses are converted to thermal impedance curves using Eqs. $6 \& 7$.

$$
\begin{aligned}
& Z_{\text {th }(m-n)}^{\text {self }}=\frac{T_{m}(t)-T_{n}(t)}{P_{\text {self }}} \\
& Z_{t h(m-n)}^{\text {cross }}=\frac{T_{m}(t)-T_{n}(t)}{P_{\text {self }}}
\end{aligned}
$$

where ' $m$ ', \& ' $n$ ', respectively corresponds to any two consecutive nodes.

\section{B. Thermal Parameter extraction}

By fitting the step response equation (Eq.8) to the transient thermal impedance curves, $3^{\text {rd }}$ order thermal equivalent Foster RC pair parameters can be obtained. Particle Swam Optimization curve fitting algorithm [17] has been used to fit Eq. 8 to the impedance data.

$$
Z_{t h}(t)=\sum_{i} R t h_{i} *\left(1-e^{\frac{-t}{R t h_{i}^{*} C t h_{i}}}\right)
$$

where, $R_{t h i} \& C_{t h i}$ respectively corresponds to thermal resistance and thermal capacitance at the $i$ th term. 


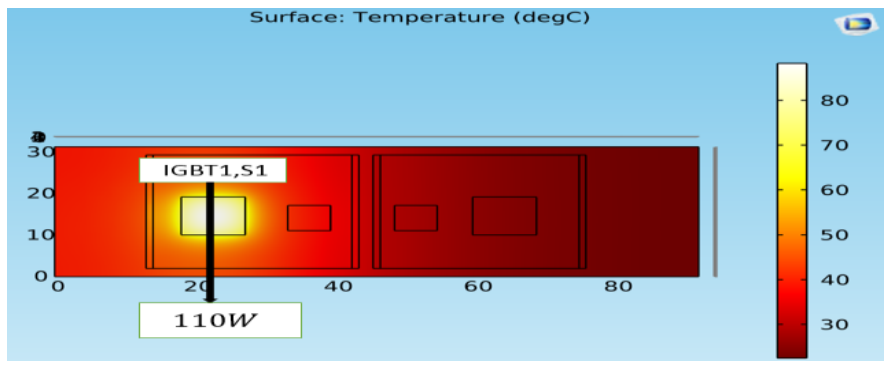

(a)

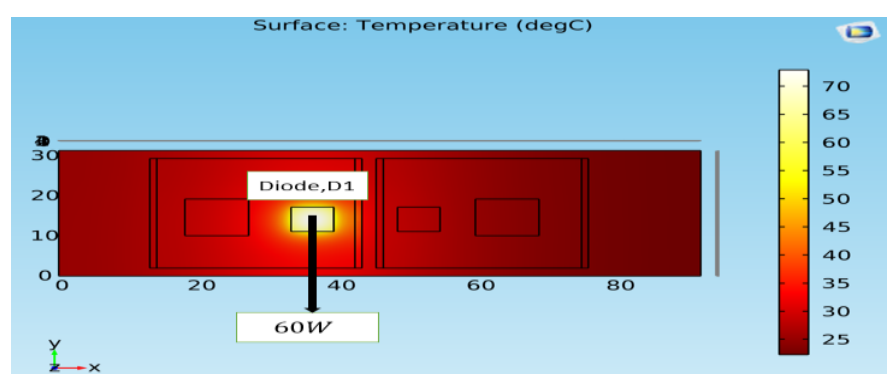

(b)

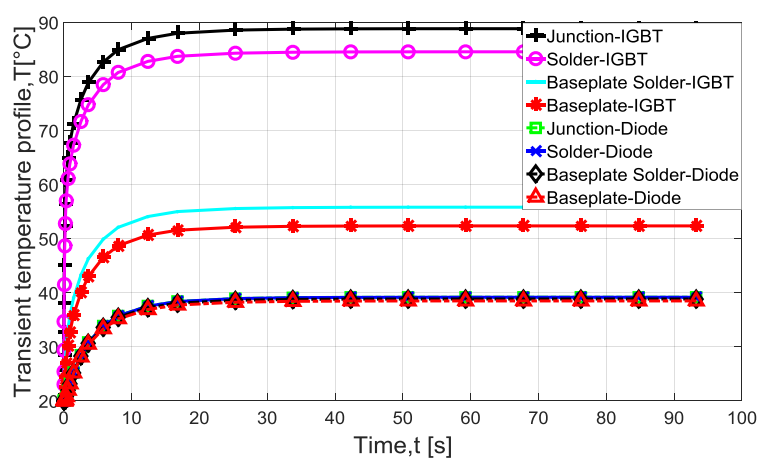

(c)

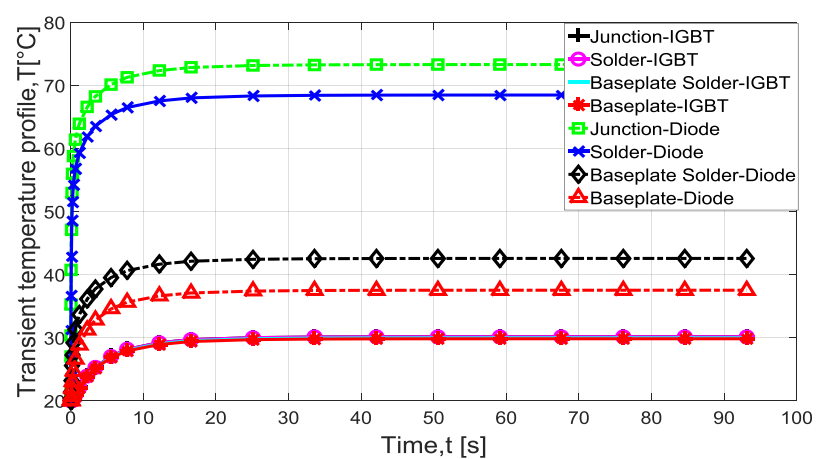

(d)

Fig. 4. (a) Temperature distribution at $t=100$ s. A power loss of $110 \mathrm{~W}$ is applied to the IGBT chip (b) Temperature distribution at $t=100 \mathrm{~s}$. A power loss of $60 \mathrm{~W}$ is applied to the Diode chip (c) Transient temperature response of IGBT (d) Transient temperature response of Diode. In (c), the temperature curves for Junction-Diode, solder-diode, Baseplate-solder-diode, and the baseplate-diode almost overlap each other. In (d), the temperature curves for Junction-IGBT, Solder-IGBT, Baseplate-solder-IGBT, and the baseplate-IGBT almost overlap each other.

The analysis of thermal coupling has been carried out using a simplified thermal network in which, the cross-heating network is modelled using the nodes at the junction and at the heatsink only and the RC pairs for this network are extracted to represent all the layers between the two nodes. The extracted parameters are listed in Tables III-VI.

Table III. Foster network RC Parameters for IGBT Self-heatıng

\begin{tabular}{|c|c|c|c|c|}
\hline Layer & $\mathrm{R \& C}$ & 1 & 2 & 3 \\
\hline \multirow{2}{*}{$\begin{array}{c}\text { Junction- } \\
\text { Solder } \\
\end{array}$} & $R_{\text {thi }},{ }^{\circ} \mathrm{C} / \mathrm{W}$ & 0.0264 & 0.0023 & 0.0109 \\
\hline & $C_{t h i}, J /{ }^{\circ} \mathrm{C}$ & $1.13 \mathrm{e}-34$ & 40.86 & 0.4713 \\
\hline \multirow{2}{*}{$\begin{array}{c}\text { Solder-DBC } \\
\text { solder }\end{array}$} & $R_{t h i}{ }^{\circ} \mathrm{C} / \mathrm{W}$ & 0.0114 & 0.0794 & 0.1708 \\
\hline & $C_{t h i}, J /{ }^{\circ} \mathrm{C}$ & 112.37 & 0.2118 & .4804 \\
\hline \multirow{2}{*}{$\begin{array}{l}\text { DBC solder- } \\
\text { Baseplate }\end{array}$} & $R_{t h i},{ }^{\circ} \mathrm{C} / W$ & .0038 & $6.36 \mathrm{e}-20$ & 0.0277 \\
\hline & $C_{t h i}, J /{ }^{\circ} \mathrm{C}$ & $1.0348 \mathrm{e} 3$ & 0.08 & 4.44 \\
\hline \multirow{2}{*}{$\begin{array}{c}\text { Baseplate- } \\
\text { heatsink }\end{array}$} & $R_{t h i},{ }^{\circ} \mathrm{C} / W$ & 0.0973 & 0.1731 & 0.0241 \\
\hline & $C_{\text {thi }} J /{ }^{\circ} \mathrm{C}$ & 5.7464 & 22.67 & 435.15 \\
\hline
\end{tabular}

Table IV. Foster network RC Parameters for diode cross-heating

\begin{tabular}{|c|c|c|c|c|}
\hline Layer & $\mathrm{R} \& \mathrm{C}$ & 1 & 2 & 3 \\
\hline \multirow{2}{*}{$\begin{array}{c}\text { Junction- } \\
\text { heatsink }\end{array}$} & $R_{\text {thi }}{ }^{\circ} \mathrm{C} / \mathrm{W}$ & 0.0087 & $2.17 \mathrm{e}-47$ & 0.166 \\
\cline { 2 - 5 } & $C_{t h i}, J /{ }^{\circ} \mathrm{C}$ & $2.09 \mathrm{e} 3$ & $1.5 \mathrm{e}-27$ & 25.97 \\
\hline
\end{tabular}

Table V. Foster network RC Parameters for diode self-heating impedance.

\begin{tabular}{|c|c|c|c|c|}
\hline Layer & $\mathrm{R} \& \mathrm{C}$ & 1 & 2 & 3 \\
\hline \multirow{2}{*}{$\begin{array}{c}\text { Junction- } \\
\text { Solder }\end{array}$} & $R_{\text {thi }},{ }^{\circ} \mathrm{C} / W$ & 0.0032 & 0.0593 & 0.0248 \\
\cline { 2 - 5 } & $C_{\text {thi }}, J /{ }^{\circ} \mathrm{C}$ & 29.55 & $8.17 \mathrm{e}-15$ & 0.2075 \\
\hline Solder-DBC & $R_{t h i},{ }^{\circ} \mathrm{C} / W$ & 0.1081 & 0.2131 & 0.1123 \\
\cline { 2 - 5 } solder & $C_{\text {thi }}, J /{ }^{\circ} \mathrm{C}$ & 0.1011 & 0.1753 & 1.2524 \\
\hline \multirow{2}{*}{$\begin{array}{c}\text { DBC solder- } \\
\text { Baseplate }\end{array}$} & $R_{t h i},{ }^{\circ} \mathrm{C} / W$ & 0.0043 & $2.51 \mathrm{e}-19$ & 0.08 \\
\cline { 2 - 5 } & $C_{\text {thi }}, J /{ }^{\circ} \mathrm{C}$ & 902.18 & 0.0857 & 1.26 \\
\hline $\begin{array}{c}\text { Baseplate- } \\
\text { heatsink }\end{array}$ & $R_{t h i},{ }^{\circ} \mathrm{C} / W$ & $3.357 \mathrm{e}-19$ & 0.1645 & 0.1275 \\
\cline { 2 - 5 } & $C_{\text {thi }}, J /{ }^{\circ} \mathrm{C}$ & $1.52 \mathrm{e}-10$ & 28.33 & 4.2 \\
\hline
\end{tabular}

Table VI. Foster network RC Parameters for diode cross-heating impedance

\begin{tabular}{|c|c|c|c|c|}
\hline Layer & $\mathrm{R} \& \mathrm{C}$ & 1 & 2 & 3 \\
\hline \multirow{2}{*}{$\begin{array}{c}\text { Junction- } \\
\text { heatsink }\end{array}$} & $R_{\text {thi }},{ }^{\circ} \mathrm{C} / \mathrm{W}$ & 0.1593 & 0.0062 & 0.0042 \\
\cline { 2 - 5 } & $C_{\text {thi }} \mathrm{J} /{ }^{\circ} \mathrm{C}$ & 29.1 & 743.8 & $6.93 \mathrm{e} 3$ \\
\hline
\end{tabular}

\section{ANALYSIS OF AN IGBT-DIODE PAIR IN AN INVERTER}

\section{A. Electro-Thermal Model of an Inverter}

The method detailed above has been used to analyse the thermal behaviours of an IGBT-diode pair in an IGBT module that is used in a conventional three-phase voltage source inverter. Fig. 5 illustrates the converter electrical circuit that is coupled to the thermal network circuit for the IGBT-diode pair. For the calculation of the power dissipations in the IGBT module, the parameters, equations and look-up tables for the modelling of the converter are adapted from the manufacturer's datasheet [14]. For modelling the conduction losses in the IGBT, $V_{C E}$ (the voltage drop in the device) has been approximated as a function of the collector current $I_{C}$. For the conduction loss calculation in the diode, the forward voltage drop has been represented as a function of the forward current. To take into account of the temperature dependency of the losses in the IGBT device, multiple loss-surfaces for a range of different operating temperatures are included in the form of a look-up table [18]. The temperature dependent switching losses in the IGBT and the diode are also included. Fig. 6 shows the predicted loss profiles in the IGBT and the diode.

For the thermal analysis, the parameters in Tables III-VI are used in the thermal network circuit model which is shown in Fig. 7. For the IGBT (or diode), the circuit consist of four branches of $3^{\text {rd }}$ order RC Foster cells that are connected in 
series. The thermal branches correspond to the junction to solder, chip solder to baseplate solder, baseplate solder to baseplate and the baseplate to heatsink thermal impedance respectively. The cross-heating has been represented by a $3^{\text {rd }}$ order RC Foster cell for the junction to heatsink impedance. As shown in Eq. 1, the total junction temperature of the IGBT or the diode consists of the contribution from self-heating, crossheating, and the ambient temperature.

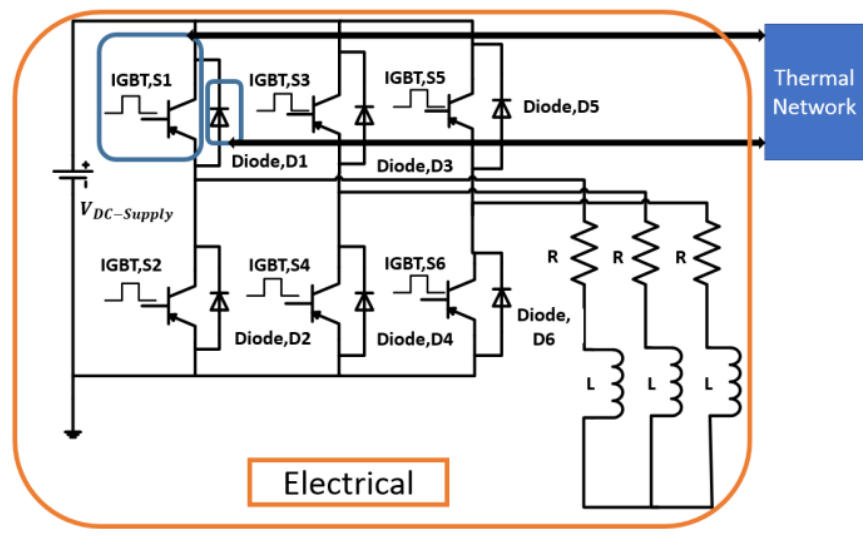

Fig. 5. Coupled Electro-Thermal network circuit for a converter.

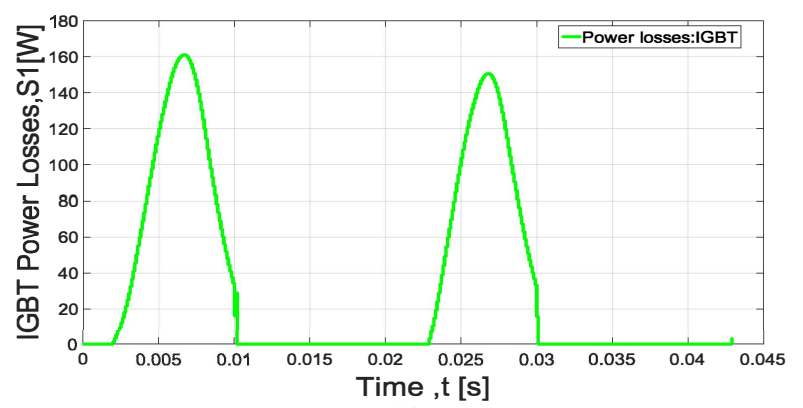

(a)

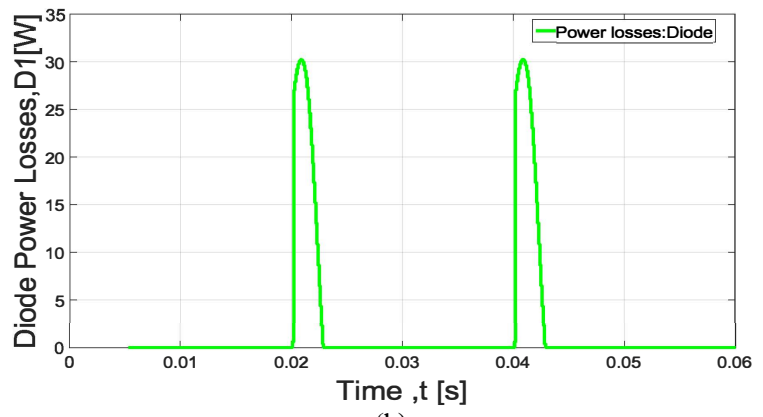

(b)

Fig. 6. Average loss profiles of IGBT \& Diode

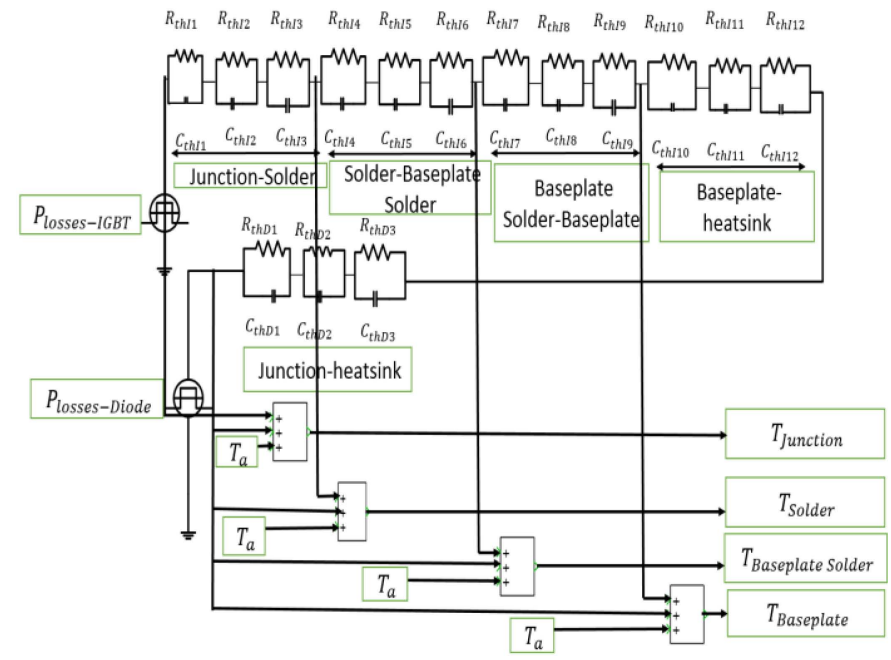

Fig. 7. Thermal network including the thermal coupling between IGBT and diode

\section{B. Thermal coupling effect analysis}

Pulsed power loss profiles of $50 \mathrm{~Hz}$ for the IGBT and diode in the IGBT module in the above mentioned power inverter have been generated using PLECS. These profiles are then used in the power module thermal network circuit for the analysis of the thermal coupling effect between the IGBT and the diode. The thermal circuit has also been analyzed using PLECS and total simulation time is $25 \mathrm{~s}$.

Three cases have been analyzed. In the first case, the thermal network RC parameters are derived from FEA simulation using temperature-dependent properties. In the second case, the RC parameters are derived from FEA simulation using properties that are not dependent on the temperature. In both these two cases, the cross heating impedance terms are included in the IGBT thermal network model. In the third case, the RC parameters do not contain cross-heating thermal impedance terms.

Fig. 8 shows the IGBT and diode junction temperatures for the three cases for the time period between 17 and $17.2 \mathrm{~s}$ simulation time when steady state has been reached. It can be seen in Fig. 8(a), the IGBT junction temperatures for case 1 and 2 differ by about $1.3{ }^{\circ} \mathrm{C}$, and case 1 and 3 differ by about $3.8^{\circ} \mathrm{C}$. This shows that both thermal coupling and nonlinearity of material properties affect the temperature predictions but thermal coupling has a much greater effect. Fig. 8(b) shows the junction temperature of the diode. Once again, the effects of material property and thermal coupling are significant. However, the temperature difference between case 1 and 3 is about $9.2^{\circ} \mathrm{C}$, which is much greater than for the IGBT. The temperature profile in case 1 is consistent with FEA thermal analysis results and it can be concluded that by taking into account of thermal coupling and by extracting RC parameters from FEA thermal analysis results junction temperatures can be predicted more accurately than using lumped parameter thermal network model alone.

In this work, FEA is used to extract the RC parameters only and any further thermal analysis of the power module will make use of circuit simulator only and it is relatively easy and fast. 
For example, in this work, the thermal network circuit can be solved in just 10s on a desktop PC using PLECS while the FEA thermal analysis takes over an hour. Therefore, the presented method is applicable for analysing long mission profiles.

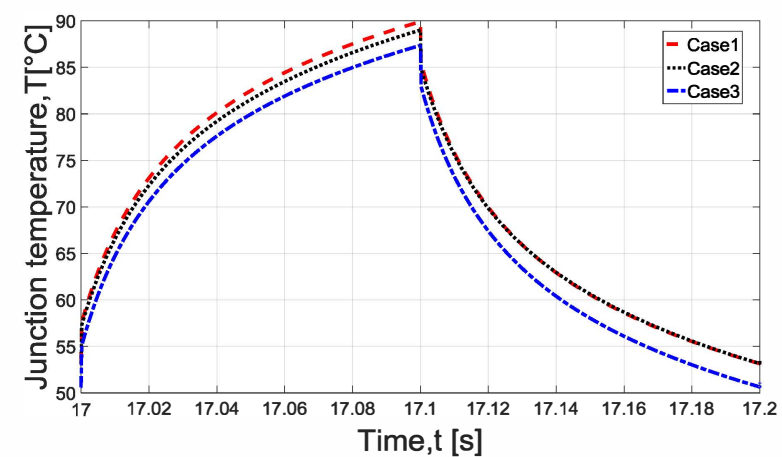

(a)

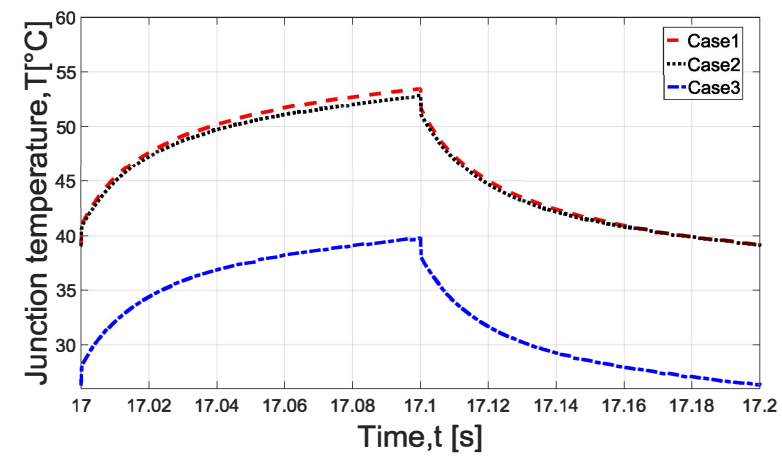

(b)

Fig. 8. The IGBT and diode junction temperature functions in (a) and (b) respectively.

\section{CONCLUSIONS}

The accuracy of temperature prediction in power modules using lumped parameter method can be improved if the interaction of the active devices is included and if the RC pair parameters are extracted from detailed FEA simulations. The improvement is more prominent for the diode temperature prediction in the inverter example that has been analysed in this work because the power dissipation in the IGBT is much higher than in the diode. By exploiting the accuracy of FEA and the speed of lumped parameter thermal network method, the proposed modelling framework is more accurate than the latter and faster than the former. This method is believed to be suitable for modelling the transient temperature response and the reliability of power devices.

\section{ACKNOWLEDGMENT}

Mohammad Shahjalal was the recipient of a Vice Chancellor Scholarship from the University of Greenwich. Hua $\mathrm{Lu}$ and Chris Bailey would like to acknowledge the financial support of EPSRC through the "Underpinning Power Electronics 2012: Components Theme" project (reference: $\mathrm{EP} / \mathrm{K} 034804 / 1)$

\section{REFERENCES}

[1] M. März, A. Schletz, B. Eckardt, S. Egelk raut and H. Rauh, "Power electronics system integration for electric and hybrid vehicles," in 2010 6th International Conference on Integrated Power Electronics Systems, Nuremberg, 2010, pp. 1-10.

[2] D. Dorrell, L. Parsa and I. Boldea, "Automotive Electric Motors, Generators, and Actuator Drive Systems With Reduced or No Permanent Magnets and Innovative Design Concepts," IEEE Transactions on Industrial Electronics, vol. 61, no. 10, pp. 5693-5695, 2014.

[3] K. Ma, M. Liserre and F. Blaabjerg, "Lifetime estimation for the power semiconductors considering mission profiles in wind power converter," in 2013 IEEE Energy Conversion Congress and Exposition, Denver, CO, 2013, pp. 2962-2971.

[4] P. Hagler, P. Henson and R. W. Johnson, "Pack aging Technology for Electronic Applications in Harsh High-Temperature Environments," IEEE Transactions on Industrial Electronics, vol. 58, no. 7, pp. 26732682, 2011

[5] C.-S. Yun, P. Regli, J. Waldmeyer and W. Fichtner, "Static and dynamic thermal characteristics of IGBT power modules," in Power Semiconductor Devices and ICs, 1999. ISPSD '99. Proceedings, the 11th International Symposium on, Toronto, Ont., 1999, pp. 37-40.

[6] N. Rinaldi, "On the modeling of the transient thermal behavior of semiconductor devices," IEEE Trans. Electron Devices, vol. 48, no. 12, pp. 2796-2802, 2001.

[7] C. S. Yun, P. Malberti, M. Ciappa and W. Fichtner, "Thermal component model for electrothermal analysis of IGBT module systems," IEEE Trans. Adv. Packag., vol. 24, pp. 401-406, 2001.

[8] M. Janicki, G. D. Mey and A. Napieralski, "Transient thermal analysis of multilayered structures using Green's functions," Microelectron. Reliab, vol. 42, no. 7, pp. 1059-1064, 2002.

[9] B. Du, J. L. Hudgins, E. Santi, S. Member, A. T. Bryant, P. R. Palmer and H. A. Mantooth, "Transient electrothermal simulation of power semiconductor devices," IEEE Trans. Power Electron, vol. 25, no. 1, pp. 237-248, 2010.

[10] M. Ishiko and T. Kondo, "A Simple Approach for Dynamic Junction Temperature Estimation of IGBTs on PWM Operating Conditions," in 2007 IEEE Power Electronics Specialists Conference, Orlando, FL, 2007, pp. 916-920.

[11] Infineon. Thermal equivalent circuit models. Application note, V1.0, 2008.

[12] T. Kojima, Y. Yamada, Y. Nishibe and K. Torii, "Novel RC Compact Thermal Model of HV Inverter Module for Electro-Thermal Coupling Simulation," in 2007 Power Conversion Conference - Nagoya, Nagoya, 2007, pp. 1025-1029.

[13] Plexim, Available: https://www.plexim.com/. (Accessed:26-May-2017)

[14] S. Bouguezzi, M. Ayadi, and M. Ghariani. "Developing a Simplified Analytical Thermal Model of Multi-chip Power Module." Microelectronics Reliability 66 (2016): 64-77.

[15] H. Li, X. Liao, Y. Li, S. Liu, Y. Hu, Z. Zeng, L. Ran, "Improved thermal couple impedance model and thermal analysis of multi-chip paralleled IGBT module," in Proc. IEEE Energy Conversion Congress and Exposition (ECCE), 2015, pp.3748-3753.

[16] A. S. Bahman, K. Ma, P. Ghimire, F. Iannuzzo and F. Blaabjerg, "A 3-DLumped Thermal Network Model for Long-Term Load Profiles Analysis in High-Power IGBT Modules," in IEEE Journal of Emerging and Selected Topics in Power Electronics, vol. 4, no. 3, pp. 1050-1063, Sept. 2016.

[17] MathWorks, Available: https://uk.mathworks.com/matlabcentral/fileexchange/48026evolutionary-curve-fitting.(Accessed:26-May-2017)

[18] U. Drofenik and J. W. Kolar, "A general scheme for calculating switching and conduction-losses of power semiconductors in numerical circuit simulations of power electronic systems," in 5th Int. Power Electronics Conf. (IPEC), Niigata, Japan, 4-8 April. 